\title{
MAPPING OF THE ENVIRONMENT USING MULTISPECTRAL SATELLITE IMAGERY
}

\author{
IVAN POTIĆ ${ }^{*}$, VANJA ŠIMUNIĆ ${ }^{2}$ \\ ${ }^{1}$ Republic Geodetic Authority, Belgrade, Serbia \\ ${ }^{2}$ Faculty of Forestry, Belgrade, Serbia
}

\begin{abstract}
Continuous environmental mapping has never been more necessary because of the fast-paced lifestyle, technology development, climate change. Monitoring changes in the environment has become one of the most important tasks todayto understand those changes and take the necessary measures to coordinate sustainable development with the emerging natural and socio-economic events. Remote sensing combined with cartography gives us the opportunity to obtain current information on the state of the environment and react suitablyin order to reduce damage to a minimum in accordance with sustainable development.
\end{abstract}

Keywords: Environment Monitoring, Supervised classification, Land Cover, Landsat 8, Town Bor.

\section{INTRODUCTION}

Classifying and interpreting satellite imagery is one of the remote sensing main tasks. This is most commonly used to analyze multispectral satellite imagery, which is presented bypixel classification from animagery into a spectral class, representing classification.

There are two types of classification: supervised and unsupervised classification. As stated by Richards, 1993 supervised classification is the primary method of obtaining quantitative data from multispectral satellite imagery. To use this method, it is necessary to know the part of the area being analyzed to obtain from these "known" pixels enough data to classify the other parts of the area being monitored. This step is called "training". Once trained, the "classifier" then classifies the entire imagery (area) by the classes we have defined (Figure 1).

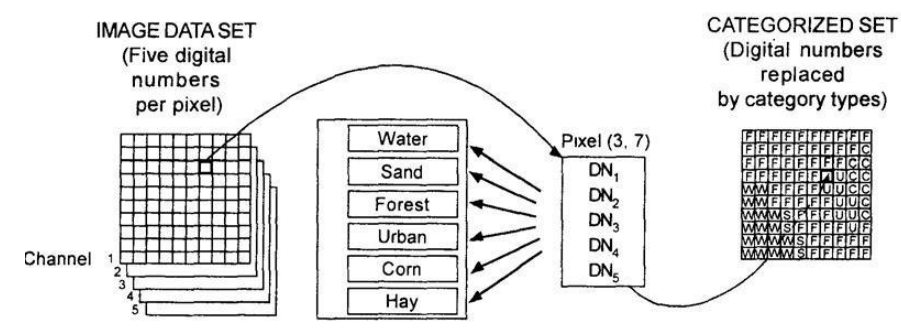

Figure 1. Supervised classification main steps.

Source: Reddy, 2008.

The most commonly used method for supervised classification is "maximum likelihood classification" (MLC). This classification uses imagery data to estimate mean and variance categories, which are used to estimate probability (Campbell, 1996).

Geospatial changes are very common in the environment. Therefore, remote sensing provides proper tool to detect

*Corresponding author: ipotic@ gmail.com environment state at given moment and map them. This is very important for afflicted areas where the environment is severely influenced by human activities, such as open mines.

Cartographic modellingis often used for presenting the state of the environment in geography and related fields. Researchers use cartographic methods to present their results which have a geospatial component, as for the changes in forest cover (Valjarević et al., 2018; Potić et al., 2017) and vegetation cover change in sensitive areas (Potić et al., 2015). In the environmental stress analysis, GIS, remote sensing and cartographic methods used for processing geospatial data is also employed to present the influence of small hydropower plants on the environment (Potić, 2018), wildfire stress analysis (Potić et al., 2017), major infrastructure projects (Potić \& Potić, 2017). In the renewable energy field, different GIS and remote sensing approaches for mapping and selecting the best locations for solar power plants (Potić et al., 2016; Valjarević, 2016) and small hydropower plants (Potić, 2018; Goyal et al., 2015). Presenting the results of the GIS analysis for the climatic elements, specific climatic indices and field research data is also convenient to employ cartographic modelling (Ivanović et al., 2016). Remote sensing and GIS also have notable role in research related to the impact of high-rise buildings on generating heat islands (Đorđević et al., 2019).

For the multispectral analysis, the area near the town of Bor, located in northeastern Serbia, in the Timok region, Borska River valleywas selected. The altitude of the city is $360 \mathrm{~m}$. The landscape is dominated by large open mines, factory chimneys and surrounded by the southern Carpathian Mountains and Borsko Lake (Stanković, 2001) (Figure 2).

The natural environment of the town of Bor primarily consists of forests with $37.1 \%$, while the economy is based on mining and metallurgy. Despite the large forests area, environmental pollution is high. Significant economic and social problems are reflected in economy diversification, unemploymentand other problems, while the solution is seen in 
gaining new perspectives on tourism development,agricultural production, mining and development of small and medium-sized enterprises, wood processing industry, forestry (Strategic Plan for Social Policy of the City of Bor for the Period 2019-2023, 2018).

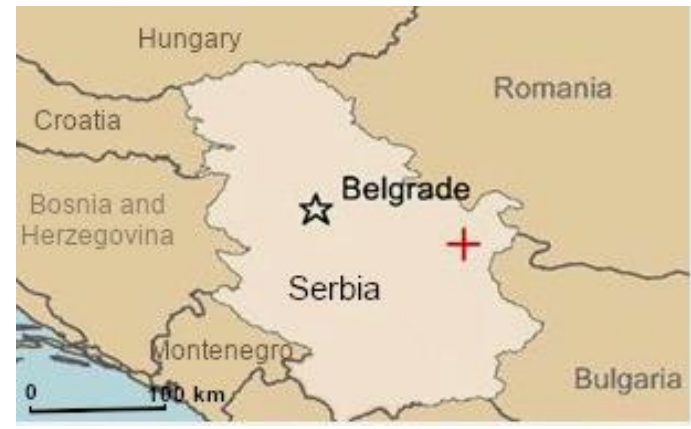

Figure 2. Area of interest.

\section{EXPERIMENTAL}

\section{Materials and methods}

Landsat 8 multispectral imagery recorded on the August 2013 were used for this research. The main features of the mission and the imagery are described as follows.

Landsat 8 consists of two instruments: an OLI (operational land imager) sensor that is similar to the Landsat 7 ETM + sensor (Figure 3), with the addition of two new spectral channels, a Coastal aerosol visible band (Band 1), which can be used to detect water and coastal terrain and a new infrared band Cirrus (Band 9) for detecting cirrus clouds. The TIRSsensor (Thermal Infrared Sensor)is used to collect data in two spectral channels of 10.6-11.9 and 11.5-12.51 $\mu \mathrm{m}$ wavelengths (Table 1, Figure 3).

Table 1. Landsat 8 Operational Land Imager (OLI) and Thermal Infrared Sensor (TIRS) (Launched February 11, 2013).

\begin{tabular}{|l|c|c|}
\hline \multicolumn{1}{|c|}{ Bands } & $\begin{array}{c}\text { Wavelength } \\
\text { (micrometers) }\end{array}$ & $\begin{array}{c}\text { Resolution } \\
\text { (meters) }\end{array}$ \\
\hline Band 1 - Coastal aerosol & $0.43-0.45$ & 30 \\
\hline Band 2 - Blue & $0.45-0.51$ & 30 \\
\hline Band 3 - Green & $0.53-0.59$ & 30 \\
\hline Band 4 - Red & $0.64-0.67$ & 30 \\
\hline Band 5 - Near Infrared (NIR) & $0.85-0.88$ & 30 \\
\hline Band 6 - SWIR 1 & $1.57-1.65$ & 30 \\
\hline Band 7 - SWIR 2 & $2.11-2.29$ & 30 \\
\hline Band 8 - Panchromatic & $0.50-0.68$ & 15 \\
\hline Band 9 - Cirrus & $1.36-1.38$ & 30 \\
\hline $\begin{array}{l}\text { Band 10 - Thermal Infrared } \\
\text { (TIRS) 1 }\end{array}$ & $10.60-11.19$ & 100 \\
\hline $\begin{array}{l}\text { Band 11 - Thermal Infrared } \\
\text { (TIRS) 2 }\end{array}$ & $11.50-12.51$ & 100 \\
\hline
\end{tabular}

Source: Landsat 8 (L8) Data Users Handbook, Version 5.0, 2019.

The novelty in Landsat 8 satellite systemis the Quality Assessment Band (QA) which reduces the impact of reflections and anomalies and provides more accurate data for scientific researchand compared to older radiometric resolution of Landsat sensors, Landsat 8 bands are 16bit (Landsat 8 (L8) Data Users Handbook, 2019).

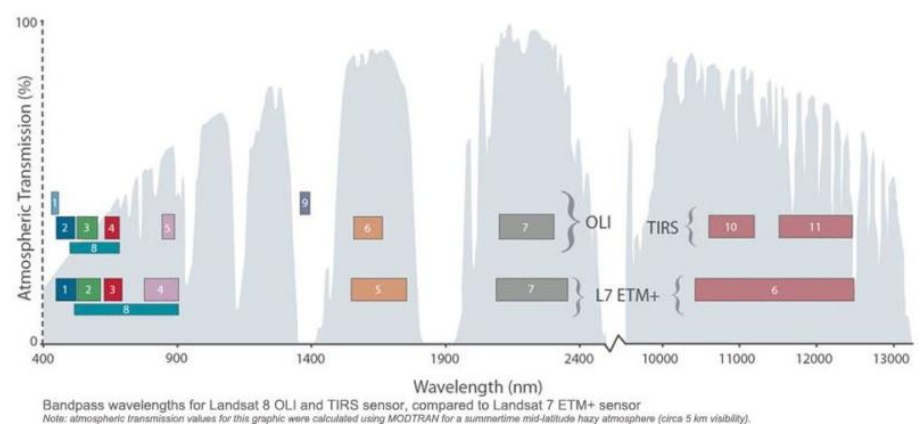

Figure 3. Landsat 8 and Landsat 7 multispectral bands. Source: Landsat 8 (L8) Data Users Handbook, 2019.

Three bands from the visible part of the spectrum (Blue, Green and Red) and one from the infrared part of the spectrum (near infrared) were selected for the supervised classification process in open source QGIS software.

MLC takes advantage of the mean vectors and multivariate propagation of each class and canidentify these extended classes (Liu, -). However, the effect of MLC depends on accurate estimation of the mean vector $m$ and the covariance matrix for each spectral class (Richards, 1993). When the classes are multimodally distributed then we get the wrong results, and it is adopted that an indefinite distribution of classes is made in the multivariate space (Liu, -).

The maximum Gaussian probability classifier quantifies the spectral pattern when classifying an unknown pixel. It calculates the statistical probability that a given pixel belongs to a particular class (Milanović \& Lješević, 2009).

The following steps are characteristic formaximum likelihood classification algorithm(Liu, -) (Figure 1):

a. Determination and display of required multispectral bands for land cover classification;

$b$. A training phase in which we identify the known classes from which the numerical values of the spectral signatures are obtained for each class in the scene;

c. The phase of determining the mean vectors and covariance matrices for the MLC classifier. These two parameters determine the properties of normal multivariate models.

$d$. The classification phase in which each pixel is categorized into the class to which it most likely belongs. Pixels that are not sufficiently similar to the classifier are marked as "unknown" (Reddy, 2008). The discriminant function $g(x)$ is:

$$
g(x)=-\ln \left(\left|\sum i\right|\right)-(x-m i)^{t} \sum i^{-1}(x-m i) .
$$

where $m i$ and $\Sigma i$ represent the mean vector and the covariance matrix of data from the class $\omega i$. To reduce misclassification, 
threshold values for each $T i$ value is set based on $95 \%$ of the pixel's values being classified.Threshold values can be obtainedusing formulae 2 :

$$
T i=-12.6-\ln \left(\left|\sum i\right|\right)
$$

The final MLC agorithm is :

$$
x \in \omega i \text {, if } g i(x)>g j(x) \text { and } g i(x)>T i \text { for all } j \neq i .
$$

Pixels that do not meet condition (3) are classified as "unknown" (Liu, -).

$e$.The last step is the processing and presentation of the obtained results.

Classification process started determining 7 classes to be extracted from the Landsat 8 imagery:
1) Water
5) Pastures and low vegetation
2) Polluted water
3) Forest
6) Open pit and tailings
7) Urban area

4) Agriculture

Training zones are digitized using selected pan-sharpened (15m) Landsat 8 imagery for large areas (where the areas are large enough so the training zone can be accurately digitized e.g. forest area, large water area, urban area).For zones where the boundaries are unclearly defined satellite and aerial orthophotos with high spatial resolution (Google Earth and Bing Maps 0.4 0.6m satellite orthophotos (Bing maps, 2013; Google, 2013)) were used (Figure 4).

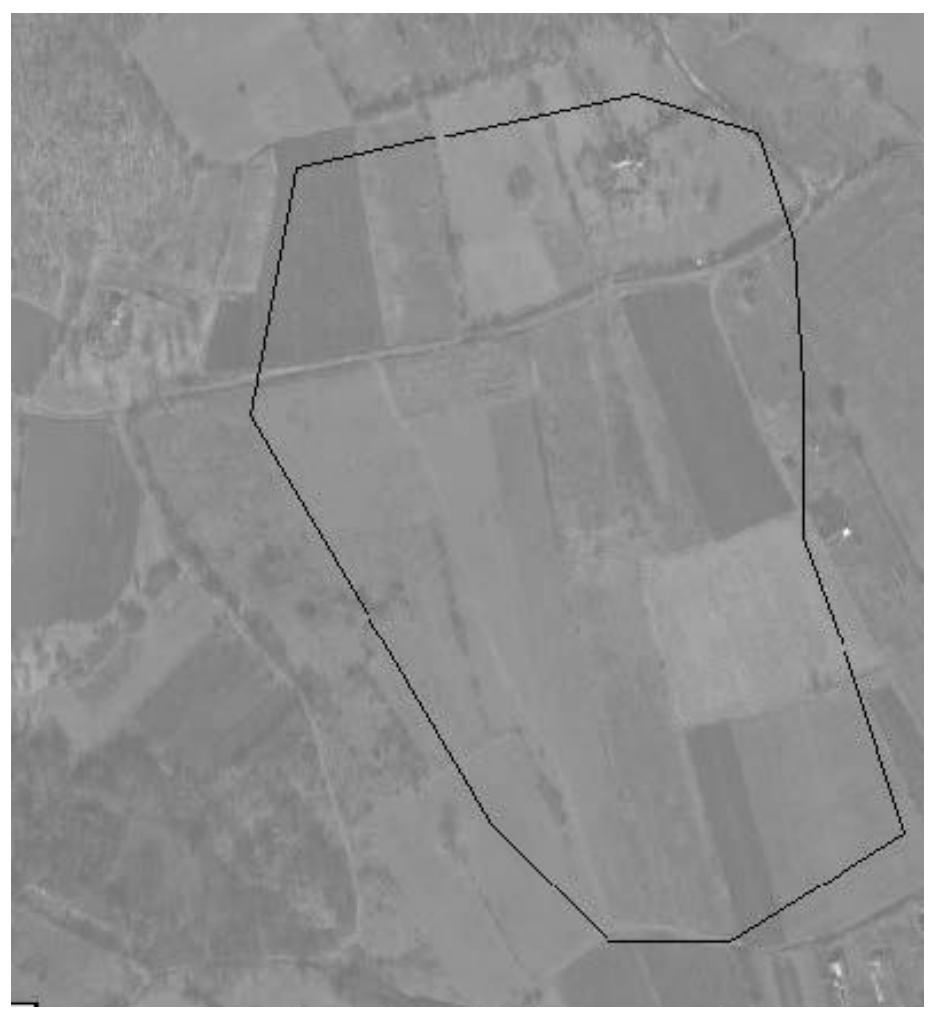

Figure 4. Training zone sample for the class Agriculture.

Source: Bing maps, 2013.
After training zone selection, software calculates statistics

\begin{tabular}{|c|c|c|c|c|c|}
\hline \multicolumn{6}{|c|}{ Univariate } \\
\hline Layel & Mirrinuun! & MexiluuII & MearI & Stu. Der. & $\wedge$ \\
\hline 1 & 7746.000 & $\exists 366.000$ & 8341.109 & 233.855 & \\
\hline 2 & 7002.000 & $\exists 285.000$ & 7819.911 & 319.804 & \\
\hline 3 & 6402.000 & 3949.000 & 7711.183 & 507.605 & \\
\hline 2 & 7699.000 & 15485.000 & 10776.698 & 1028.297 & \\
\hline \multicolumn{6}{|c|}{ Covariance } \\
\hline Layer & 1 & 2 & 3 & 4 & ^ \\
\hline 1 & 54688.357 & 71992.925 & 115323.933 & 7973.490 & \\
\hline 2 & 71992.925 & 102274.525 & 155898.410 & 74504.012 & \\
\hline 3 & 115323.933 & 155898.410 & 257662.825 & -6944.757 & \\
\hline 4 & 7973.490 & 74504.012 & .6944 .757 & 1057395.588 & \\
\hline
\end{tabular}
for each class using selected algorithm (figures 5 and 6).

\begin{tabular}{|c|c|c|c|c|c|c|c|c|c|}
\hline Class \# & Signature Name & Cobr & Red & Gree $\boldsymbol{\nabla}$ & Blue & Value & Order & Count & Prot \\
\hline $1 \nabla$ & Agriculture & & 0.285 & 0.666 & 0.602 & 12 & 12 & 3628 & 1.01 \\
\hline 2 & Pastures and low vegetation & & 0.606 & 0.616 & 0.598 & 15 & 26 & 984 & 1.01 \\
\hline 3 & Urban area & & 0.438 & 0.864 & 0.846 & 7 & 33 & 1812 & 1.01 \\
\hline 4 & Water & & 0.000 & 0.149 & 0.104 & j & 39 & 311 & 1.01 \\
\hline 5 & Polluted water & & 0.000 & 0.470 & 0.932 & $\overline{5}$ & 44 & 424 & 1.01 \\
\hline 6 & Open pit and tailings & & 0.477 & 1.000 & 1.000 & 13 & 53 & 2192 & 1.01 \\
\hline 7 & Forest & & 0.809 & 0.328 & 0.374 & 1] & 60 & 5059 & 1.01 \\
\hline
\end{tabular}

Figure 5. Agriculture training zones statistics.

Figure 6. Signature editor classes from training zones.

Using above mentioned data, algorithm classifies image pixels into the given classes.

\section{RESULTS}

Final MLC algorithm result can be cartographically presented as a map of the area at a given moment, showing the state of the environment.

In this case, the class Urban areacontainsroads that extend along the studied area, as well as bare rocks for which there is no separate class as for the roads, which can be seen in the north and northeast part of the area. Water and polluted water classes, as well as the forest and open pitand tailings are very well classified. The Agriculture class includes areas with low grass and bare soil, while a similar problem occurs in the Pastures and Low Vegetation class. Class overlap is one of a major problem with supervised classification. In this case, no Unknown class is obtained, which means that the algorithm recognized all the pixels, and that there was little overlap, but that we could not inevitably say that certain classes were precisely defined (figure 7). Depending on the quality of the training zone, we will receive better quality data. 


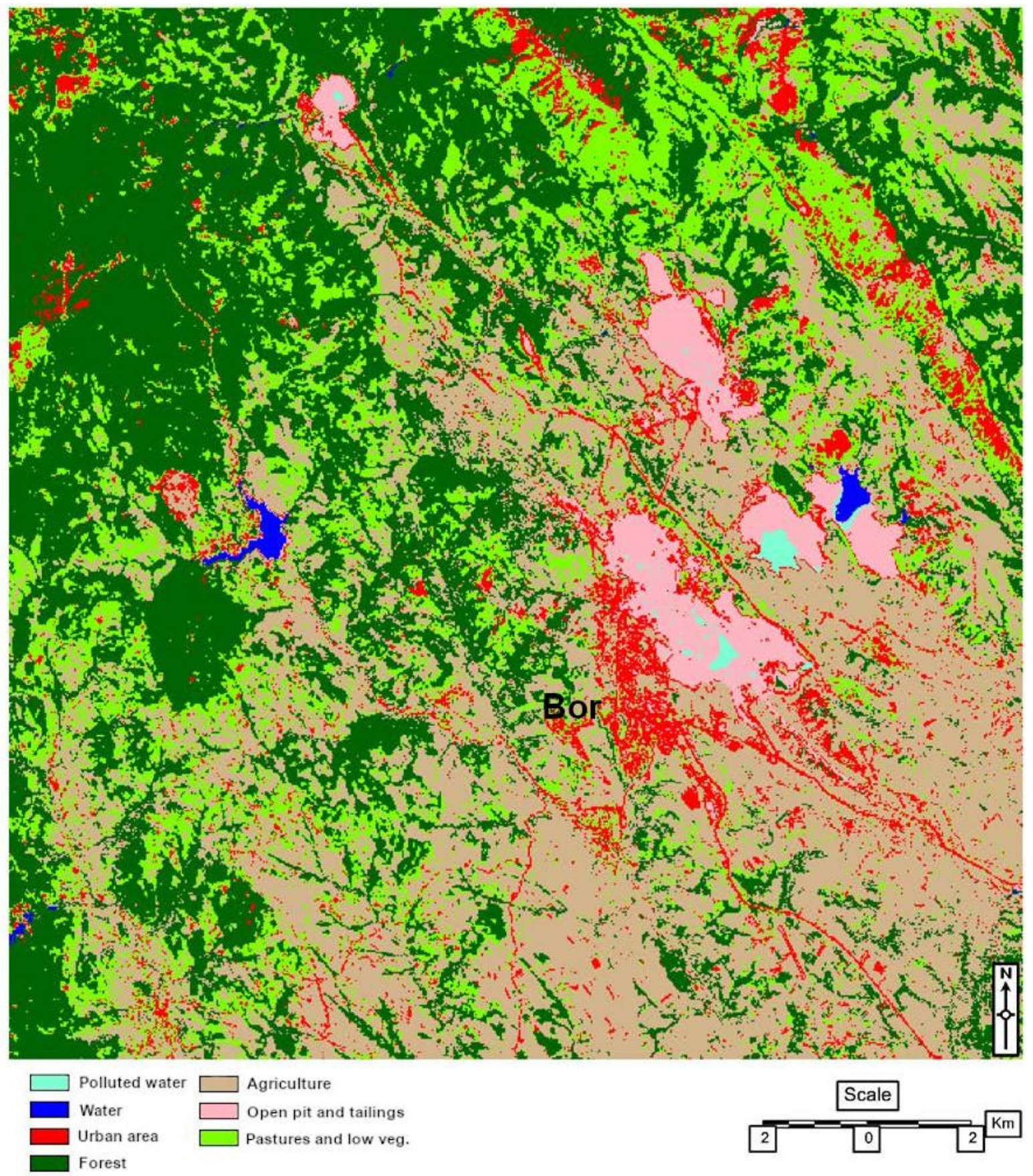

Figure 7. Research area Land Cover map.

\section{CONCLUSION}

Using the supervised multispectral analysis, we were able to obtain a land cover map of the area of interestwhich covers the town of Bor and the surrounding area, located in northeastern Serbia. From the obtained land cover map we can confirm the relative accuracy of the obtained classes, where out of 7 selected, four completely coincide with the situation on the ground, while in the three classes we have noticedmisclassified mixed pixels, which requires an increase in the number of classes and new supervised analysis iterations to obtain 10 classes that would accurately represent the land cover of the area. Class mixing and the difference between terrain (shown in higher resolution imagery) may also be due to the small spatial resolution of $30 \mathrm{~m}$ per pixel. Overall, the results are satisfactory and could be used to derive land cover map for which the supervised maximum likelihood classification (MLC) is designed.

Supervised classification advantages are:

- The analyst has control of training zones choice;

- The selected information category menu is specific to the region and purpose; 
- This classification is usually related to specific surfaces of known classes;

- With this classification, the analyst has no problem in aligning the spectral regions (on the final map) with the interest information categories.

- An operator can detect serious errors by examining the data (to determine if they are accurately classified, which does not mean that the other classes are correct).

The disadvantages and limitations of the supervised classification are numerous. The defined categories may not be the same as in the field. Data are often defined by information categories, and only secondary to spectral properties, which can be selected by the analysts. This is used when we have large areas. The analyst may have trouble matching the data on the maps and aerial images with those classified from the imagery. This type of classification may not recognize and/or represent specific or unique categories (Mulahusić, 2007).

\section{REFERENCES}

Campbell, B. A. 1996. Introduction to Remote Sensing. In Introduction to Space Sciences and Spacecraft Applications. London: Taylor and Francis.

Đorđević, T., Potić, I. \& Milanović, M. 2019. Quantification of the Impact of High-rise Buildings on Generating Heat Islands in the Area of the Realisation of the Special Purpose Plan "Belgrade Waterfront" in Belgrade. In Mihajlović, M. (Eds.), Conference proceedings International scientific conference Environmental impact of illegal construction, poor planning and design IMPEDE 2019, 10 - 11 October 2019, Belgrade, Serbia (378-387). Association of Chemists and Chemical Engineers of Serbia (UHTS), Belgrade.

Goyal, M. K., Singh, V. \& Meena, A. H. 2015. Geospatial and hydrological modeling to assess hydropower potential zones and site location over rainfall dependent Inland catchment. Water Resour. Manage. 29: 2875.

Ivanović, R., Valjarević, A., Vukoičić, D., \& Radovanović, D. 2016. Climatic regions of Kosovo and Metohija. The University Thought-Publication in Natural Sciences, 6(1), pp 49-54. doi:10.5937/univtho6-10409

Landsat 8 (L8) Data Users Handbook, Version 5.0 (2019). Department of the Interior, U.S. Geological Survey, EROS, Sioux Falls, South Dakota.

Liu, X. (-) Supervised classification and Unsupervised classification. Harvard: Smithsonian Center for Astrophysics. ATS $670 \quad$ Class Project; Available: https://www.cfa.harvard.edu/ xliu/presentations/SRS1_proje ct_report.PDF.
Milanović, M., \& Lješević, M. 2009. Teledetekcione metode istraživanja životne sredine. Beograd: Geografski fakultet.

Mulahusić, A. 2007. Kreiranje tematskih karti na osnovu satelitskih snimaka korištenjem Maximum likelihood klasifikacije. Sarajevo: Geodetski glasnik. br. 39.

Potić, I. 2018. Geosistemska analiza višestrukih stresova životne sredine u valorizacijima lihhidro elektrana Srbije. Doctoral dissertation, University of Belgrade, Faculty of Geography.

Potić, I., \& Potić, M. 2017. Remote sensing machine learning algorithms in environmental stress detection: Case study of Pan-European south section of Corridor 10 in Serbia. The University Thought-Publication in Natural Sciences, 7(2), pp. 41-46. doi:10.5937/univtho7-14957

Potić, I., Ćurčić, N., Potić, M., Radovanović, M. \& Tretiakova, T. 2017. Remote sensing role in environmental stress analysis: East Serbia wildfires case study (2007-2017). Journal of the Geographical Institute "Jovan Cvijić" SASA, 67(3), pp. 249-264.

Potić, I., Golić, R. \& Joksimović, T. (2016). Analysis of insolation potential of Knjaževac Municipality (Serbia) using multi-criteria approach. Renewable and Sustainable Energy Reviews, 56, pp. 235-245. doi.org/10.1016/j.rser.2015.11.056

Potić I, Joksimović M \& Golić, R. 2015. Changes in vegetation cover on Staraplanina: towards sustainable management of ski resorts in sensitive areas. Bull Serb Geogr Soc 95(2), pp. $25-40$.

Reddy, A. 2008. Textbook of Remote Sensing and Geographical Information Systems. Hyderbad: BS Publications. Third Edition.

Richards, J. A. 1993. Remote sensing digital image analysis: An introduction. Springer-Verlag. second edition.

Stanković, S. 2001. Putevima Jugoslavije. Beograd: Zavod za udžbenike i nastavna sredstva.

Strategic Plan for Social Policy of the City of Bor for the Period 2019-2023 2018. Available: http://bor.rs/wpcontent/uploads/2019/04/Strateški-plan-za-socijalnu-politikugrada-Bora-za-period-2019-2023.pdf.

Valjarević, A., Djekić, T., Stevanović, V., Ivanović, R. \& Jandziković, B. 2018. GIS numerical and remote sensing analyses of forest changes in the Toplica region for the period of 1953-2013. Applied geography, 92, pp. 131-139.

Valjarević, A. 2016. GIS modelling of solar potential in Toplica region. The University Thought-Publication in Natural Sciences, 6(1), pp. 44-48.doi:10.5937/univtho6-10739

Bing maps 2013. [Bing aerial]. Retrieved in 2013, from URL: [https://www.bing.com/maps?osid=674cd93c-5ad8-4557a37e4ae51c5a801e\&cp=44.073285 22.097064\&lvl=16\&v=2 $\& s \mathrm{~V}=2 \&$ form $=$ S00027]

Google 2013. [Google satellite]. Retrieved in 2013, from URL: [https://www.google.com/maps/@44.0693725,22.0919778,1 $816 \mathrm{~m} /$ data $=! 3 \mathrm{~m} 1 ! 1 \mathrm{e} 3]$ 